\title{
An Overview of the Treatment of Tourette's Disorder and Tics
}

\author{
Humberto C. Párraga, M.D., Kara M. Harris, B.S., Karen L. Párraga, M.Ed., \\ George M. Balen Psy.D., and Cristina Cruz, M.D.?
}

\begin{abstract}
Objective: The aim of this study was to review the efficacy of various treatments for Tourette's disorder (TD) and tics. Method: This study is a historical review of the treatment modalities prior to the advent of neuroleptics. A review of doubleblind and placebo-controlled clinical trials and open studies on the use of neuroleptics and selected reports was also carried out.

Results: The literature review reveals that the treatment of TD and tics has evolved from an early history of marginally effective approaches to the advent of neuroleptics, which started a new era in TD and tic treatment, with a significantly broader range of effectiveness.

Conclusions: Although progress has been made, the literature review nevertheless reveals a great deal of confusion as related to the clinical heterogeneity of TD and tics, differences in populations, medication-dose combinations, and outcomes. However, a role for a limited number of pharmacologic agents, combined with psychosocial approaches, has been identified. There is a need for studies in larger, diagnostically homogenous samples and for the use of more sophisticated methodology, to identify intelligible models that would allow the development of more effective treatment approaches.
\end{abstract}

\section{Introduction}

B ECAUSE TICS ARE A COMPONENT of multiple disorders, classically Tourette's disorder (TD), the history of the treatment of TD parallels the treatment of tics. This overview represents a substantial effort beginning with the description of a variety of early interventions (which, at present, may be deemed only of historical interest), followed by a review of clinical studies of neuroleptics and their striking implications for the treatment of TD and tics.

\section{Historical Review}

The early history of the treatment of TD and tics includes a gamut of diverse and inventive, albeit marginally effective, approaches.

An early paper (Itard 1825) offered one of the most graphic descriptions of the methods of symptom alleviation available in the early to mid-1800s, such as "the application of leeches for 2 consecutive days monthly, and cupping in a series of areas along the spine while the patient was in a prone position." The author also recommended "drinking an emulsion of ground chicken along with the simultaneous administration of two baths with a total immersion in cold water for a duration of 3 hours for 2 consecutive days." Another prescription for one of his female patients was the application "of leeches to the vulva along with the application of cupping to the thighs while the patient lay prone for 2 hours" and the application of "leeches to the thighs while soaking the patient's feet in a mildly caustic solution after the application of valeriane powder." At last, he suggested, "cold river baths and additional cooling of the body by application of refrigerant lotions and breezes of cold air" with subsequent removal of the patient to "a place of isolation."

Reeducation with the use of massages and methodical gymnastics in cases of "severe chorea" were alleged to provide rapid and excellent results (Blache 1864). Gymnastic exercises of the involved muscles to the rhythmic accompaniment of a metronome or the pendulum of a clock were also recommended (Trousseau 1873).

Gilles de la Tourette (1885) himself acknowledged the tremendous difficulties in treating this ailment. He claimed that the one course of treatment that seemed to impact the syndrome was "isolation, in combination with the use of tonics of all sorts including iron preparations and hydrotherapy." These patients equally appeared to benefit from the "prolonged use of static electricity in combination with hydrotherapy and isolation." $\mathrm{He}$ also emphasized that these approaches could only delay the evolution of the illness rather than cure it, clarifying that all sedatives of the central nervous systems known at that time had been tried and found to be ineffective.

An article on "convulsive tics" (Guinon 1887) devoted only a few lines to the issue of treatment, recommending hydrotherapy combined with isolation. Another (Charcot 1888) cautiously stated,

Departments of ${ }^{1}$ Child Psychiatry and ${ }^{2}$ Pediatrics, Fourth Street Clinic, Springfield, Illinois. 
"we can not say that cure is certain but may count on longer or shorter intervals of arrest, either spontaneous or a sequel to the employment of serviceable measures such as hydrotherapy and gymnastics."

The value of motor discipline in tic control was demonstrated (Brissaud 1899) by the use of a method that was a combination "of immobilization of movements with movements of immobilization." The exercises were intended to teach the patient how to preserve immobility by remaining absolutely motionless as long as he could without fatigue, gradually increasing the periods of immobility, and emphasizing that "one must rest content even with the most insignificant gain." A doctoral thesis (Cruchet 1902) written in this period advocated interventions, including motor discipline, training the antagonists, respiratory drill, and gymnastics.

A very influential book Tics and Their Treatment (Meige and Feindel 1902,1907) listed a number of diverse invasive methods of intervention recommended by different practitioners, available in the late 1800 s and early 1900 s, which included the rhythmic traction of the tongue, application of mustard plasters, thoracic compression, electric shock of the phrenic nerve, and application of an actual cautery to the vertebral column. General hygiene, diet, altering the patient's lifestyle by prescribing recreation, sea voyages, time at seaside curative resorts, and hydrotherapy were mentioned along with medicinal, surgical, and orthopedic treatments. They concluded that most of the medicinal agents used at that time had been found to be ineffective in treating tics. These drugs included caffeine, coca, cocaine, arsenic, quinine, ether, chloroform, curare, atropine, laudanum, opium, morphine, chloral hydrate, Cannabis indica, zinc valerianate, and bromides.

The surgical procedures, mentioned in the same book, included the elongation, ligature, and section or resection of the spinal accessory. The authors nevertheless emphasized that surgical procedures were "applicable only to a small minority of tics, principally those of the neck." They also expressed doubts about the efficacy of the orthopedic treatment, indicating that in some instances the various forms of apparatus used to intervene for temporary relief of symptoms were more harmful than beneficial. The treatment of tics by the use of psychotherapy, conscious education, hypnotic suggestion, and reeducation in combination with surgical treatment was also emphasized as a means of maintaining the general health of the patient, including proper sleep and the use of sedatives such as bromides to ensure the patient's rest (Brain 1928). In the treatment of children, the same author encouraged the whole household be united "in a conspiracy to take no notice of the child's movements" to promote reduction of symptoms. Punishment and reproof of the child for exhibiting symptoms were prohibited. If lack of improvement resulted, the child was "sent to relatives in another town for a time, or admitted to a suitable hospital."

The use of intensive psychotherapy was actively promoted (Mahler and Rangell 1943). Later, persuasion, reeducation, autogenic training, and psychoanalysis were also recommended (Mahler and Gross 1945; Mahler and Luke 1946). Bimedial frontal leucotomy (Baker 1962), carbon dioxide inhalation (McDonald 1963; Downing et al. 1964), experimental hypnotherapy (Erickson 1964), social-psychiatric management (Faux 1966), and behavior management (Clark 1966) were also reported.

Group therapy, family therapy, biofeedback, insulin coma, electroconvulsive treatment, acupuncture, and transcendental meditation were mentioned as additional treatment modalities for TD with inconsistent results (Shapiro et al. 1978).

\section{Contemporary Review}

\section{Classic or typical antipsychotics}

The advent of the neuroleptics started a new era in the treatment of TD and tics. Antipsychotics are thought to act primarily by blocking dopamine receptors, thus decreasing dopaminergic input from the substantia nigra and ventral tegmentum to the basal ganglia.

Multiple clinicians (Seignot 1961; Challas and Brauer 1963; Chapel et al. 1964; Abuzzahab and Anderson 1973; Shapiro et al. 1973) reported the efficacy of haloperidol (HAL) in the treatment of tics and TD (Table 1). HAL was approved by the FDA for the treatment of adult TD patients in 1969 and for children in 1978. However, a number of nonuniversal adverse and side effects (cognitive blunting, weight gain, lethargy, and akathisia) limited its use (Mikkelsen et al. 1981).

Pimozide was the most widely used alternative to HAL. Approved by the FDA in 1984 for the use in TD patients, it was touted as having lower potential for adverse effects. Pimozide was used with good results in multiple studies (Debray et al. 1972; Shapiro and Shapiro 1984; Regeur et al. 1986; Sallee et al. 1997), one of which showed a mean percentage decrease of symptoms at the endpoint of $71 \%$ for pimozide and $62 \%$ for HAL.

Penfluridol was used with significant symptomatic improvement and fewer adverse effects compared with HAL, but concerns about its carcinogenic potential limited its use (Parihk et al. 1979; Shapiro et al. 1983a).

Phenothiazines such as fluphenazine and trifluoperazine were compared with HAL in a double-blind, placebo-controlled study in 10 TD patients and all three active medications were better than placebo in tic suppression. None of these medications statistically proved to be better than the other (Borison et al. 1982). In another open study, 21 TD patients, considered to be resistant to HAL, were subsequently treated with fluphenazine, with decrease of tics, improvement of efficacy, and fewer adverse affects (Goetz et al. 1984).

Chlorpromazine, trifluoperazine, perphenazine, and thioridazine were also used with lesser efficacy and the limitations were a cohort of significant adverse effects including photosensitivity, dermatitis, extrapyramidal symptoms, and blood and liver dyscrasias (Shapiro et al. 1988).

In summary, the typical antipsychotics have demonstrated efficacy in the treatment of tics and TD. However, a number of nonuniversal side and adverse effects of variable degree have limited their use.

\section{Tricyclic antidepressants}

Tricyclic antidepressants (TCAs) became the focus of significant controversy throughout the years because of contradictory reports (Table 2) of tic precipitation, exacerbation, no tic changes, and tic amelioration.

Precipitation of tics by TCAs was suggested in an incidental reference (Golden 1977) in which imipramine (IMI) was listed among the "stimulant" drugs taken by 32 patients with TD, before and after their TD became manifested. Precipitation of tics consistent with TD during IMI administration was also reported in two children with apparent genetic vulnerability (Párraga and Cochran 1992).

Exacerbation of TD by IMI (Fras and Karlavage 1977; Fras 1978) and mixed results with clomipramine (CMI) and desipramine (DMI) were reported (Caine et al. 1979a). 


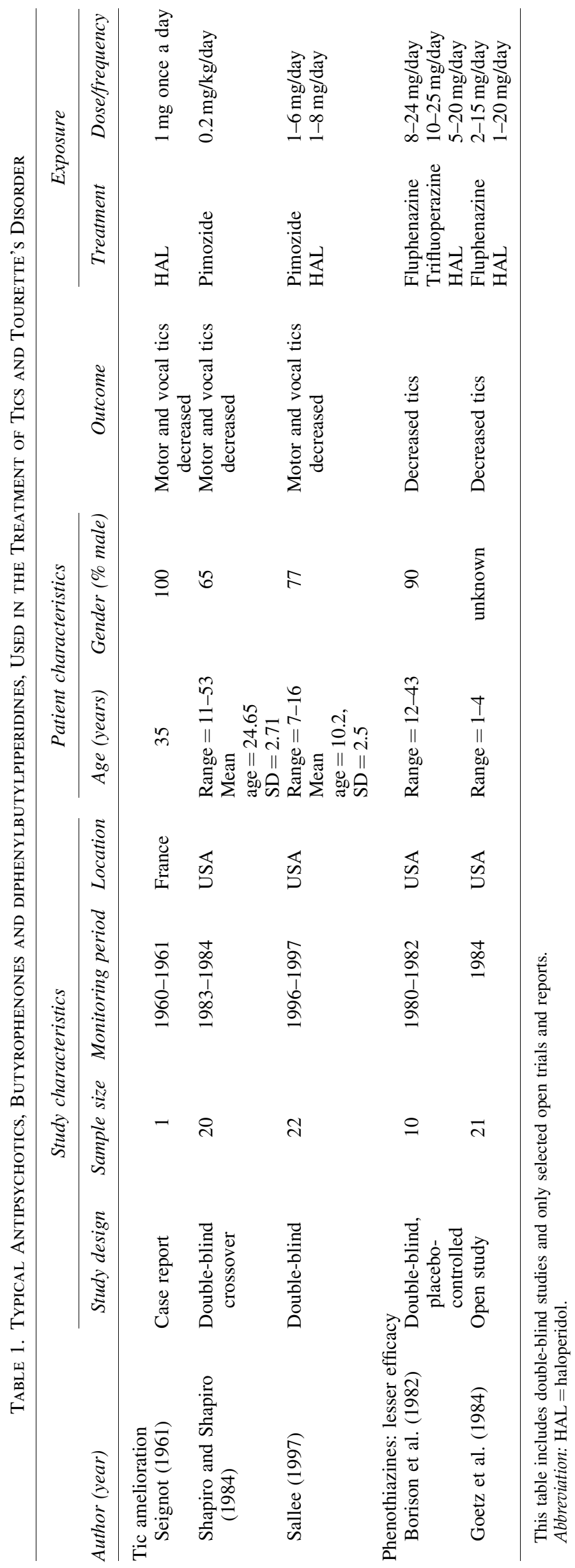




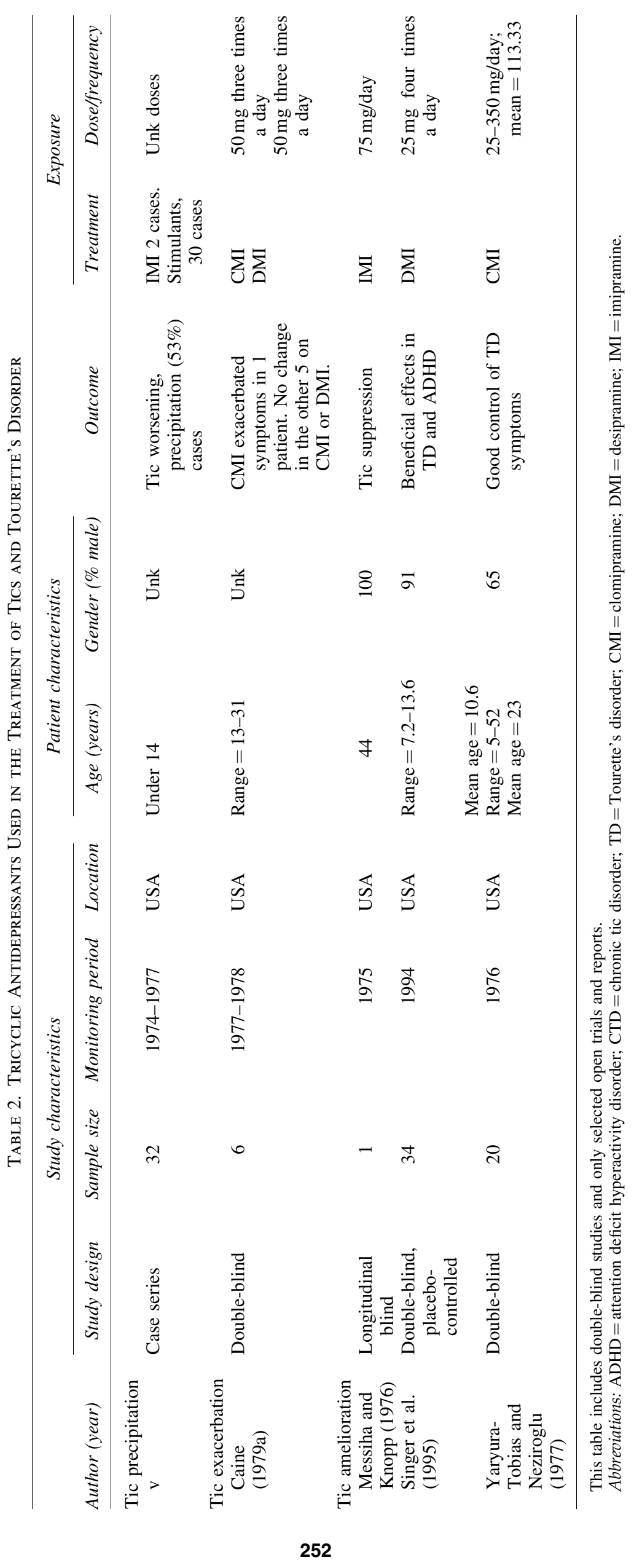


No tic worsening by IMI in a boy with TD and attention deficit hyperactivity disorder (ADHD), with significant improvement of ADHD symptoms (Dillon et al. 1985), and control of panic attacks in another boy with TD and panic disorder (Sverd 1988) were reported.

Beneficial effects of IMI on TD with tic amelioration were reported (Messiha and Knopp 1976; Sandyk and Bamford 1988). DMI was found to be effective for the treatment of boys with ADHD and tics (Riddle et al. 1988; Spencer et al. 1993a). A doubleblind, placebo-controlled protocol (Singer et al. 1995) was used in children with TD and ADHD to examine the ability of clonidine and DMI to modify ADHD behaviors. The results of this study suggested that DMI was superior to clonidine and may be a useful alternative for the treatment of symptoms of ADHD in children with TD.

CMI was reported to have beneficial effects in two TD patients who had failed to respond to various treatments, prompting remission of motor symptoms and amelioration of obsessive-compulsive disorder (OCD) (Yaryura-Tobias 1975). Another study (Yaryura-Tobias and Neziroglu 1977) also suggested beneficial effects of CMI on TD patients. CMI was later used to treat a boy with TD and comorbid OCD with excellent response (Ratzoni et al. 1990), shown by an almost complete remission of OCD and cessation of motor tics around his eyes and nose.

Finally, nortriptyline was used with beneficial effects in children with chronic ADHD and chronic tic disorder (Spencer et al. 1993b).

In summary, TCAs have shown efficacy in the treatment of TD and tics, but their use has significantly decreased through the years because of risks of cardiovascular toxicity, EEG changes, seizures, and incoordination among others.

\section{Psychostimulants}

Psychostimulants (Table 3) have also been reported to cause tic precipitation, exacerbation, no tic changes, and amelioration of tics and TD symptoms.

Precipitation of TD and tics by amphetamines, methylphenidate (MPH) (Golden 1974; Pollak et al. 1977), pemoline (Mitchell and Mattews 1980; Lowe et al. 1982), and dexmethylphenidate hydrochloride (Silva et al. 2008) have been reported.

Exacerbation of tics and TD by amphetamines (Singer 1963; Cohen et al. 1978; Feinberg and Carroll 1979), MPH (Fras and Karlavage 1977), and MPH, pemoline, and dextroamphetamines (DEX) (Price et al. 1986) were also reported.

Some researchers (Denckla et al. 1976; Shapiro and Shapiro 1981) found no evidence of tic changes or worsening by psychostimulants, if properly dosed, in patients with preexisting tics or TD. Similarly, in a double-blind, placebo-controlled study of children with TD and ADHD, MPH improved ADHD symptoms without exacerbating tics in 9 of the 11 patients; of the other 2,1 showed no change and the other showed behavioral deterioration (Konkol et al. 1990). In another double-blind, placebo-controlled study of children with ADHD and tic disorder, MPH effectively suppressed hyperactive, disruptive, and aggressive behaviors without increasing tic severity (Gadow et al. 1995). Still other placebocontrolled, double-blind studies (Law and Schachar 1999; Gadow et al. 1999) of ADHD children treated with MPH, at doses based on the typical titration procedure, during long-term treatment, did not produce significantly more tics than the placebo in children with or without preexisting tics.

Some literature also suggests that stimulants might have a beneficial effect on TD or reduce the long-term severity of TD and tics by desensitizing catecholamine receptor sites (Comings and Comings 1987; Gadow et al. 1992). In a review of TD patients treated with stimulants, about $10 \%$ to $20 \%$ showed a decrease in tics as well as hyperactive/disruptive behaviors (Gadow and Sverd 1990).

Another placebo-controlled, double-blind crossover treatment trial using a wide range of doses of MPH and DEX in subjects with ADHD comorbid with TD showed the majority experienced improvement in ADHD symptoms, with acceptable effects in tics. MPH was better tolerated than DEX. Adverse effects, including tic exacerbation, were reversible in all cases (Castellanos et al. 1997).

Dexmethylphenidate hydrochloride has not been studied in children with preexisting tics or TD. However, in a multicenter, double-blind crossover study of 82 children, 6-12 years of age (which specifically excluded children with tic disorder or TD), tics were reported as an adverse event in two patients (2.4\%) at a dose of $30 \mathrm{mg} /$ day (Silva et al. 2008).

Methylphenidate transdermal patches have been available since 2006, with only a premarketing caution about its use in children with tics (Palumbo et al. 2004), but they have not been well studied.

Lisdexamfetamine dimesylate, in a randomized, double-blind, forced-dose, parallel-group study, was shown to be effective in treating ADHD symptoms with the potential to precipitate tics only in a small percentage of patients (Biederman et al. 2007).

In summary, the literature indicates there is no evidence that properly dosed stimulants can cause or exacerbate tics and that tic exacerbations, if they occur, are reversible. Some literature also suggests that psychostimulants might have beneficial effects on TD and tics in patients with comorbid ADHD. However, caution should be exercised in dosing the stimulants, because certain individuals may be more predisposed to tics.

\section{Nonstimulants}

Nonstimulants, such as atomoxetine, have been introduced as an alternative to stimulants, and initial data (McCracken et al. 2003) indicated that this medication did not induce tic activity. This study randomly assigned patients to a double-blind treatment with placebo or atomoxetine $(0.5-1.5 \mathrm{~kg} / \mathrm{day})$ for $\sim 18$ weeks. The atomoxetine group showed a significantly greater numeric reduction of tic severity (group data) on the Yale Global Tic Severity Scale (YGTSS). However, there are more recent reports of tic exacerbation and precipitation during atomoxetine treatment (Lee et al. 2005).

\section{$\alpha$-Adrenergic medications}

$\alpha$-Adrenergic drugs primarily activate presynaptic autoreceptors in the locus ceruleus, reducing norepinephrine release and turnover in the cerebral cortex. Decreased norepinephrine levels in the thalamus may be responsible for the sedation reported during the use of clonidine and guanfacine.

Clonidine has been used since the early 1970s as an antihypertensive agent and since 1980 to treat TD and tics (Table 4) with contradictory reports of its efficacy. After the initial descriptions of clonidine treatment in children with TD with favorable response (Cohen et al. 1980; Bruun 1982), other studies failed to show any significant benefits from its use (Shapiro et al. 1983b; Goetz et al. 1987). Another long-term (60 weeks), single-blind, placebocontrolled study of 13 patients with TD found that 6 had a beneficial response, whereas an equal number had a poor to marginal response 


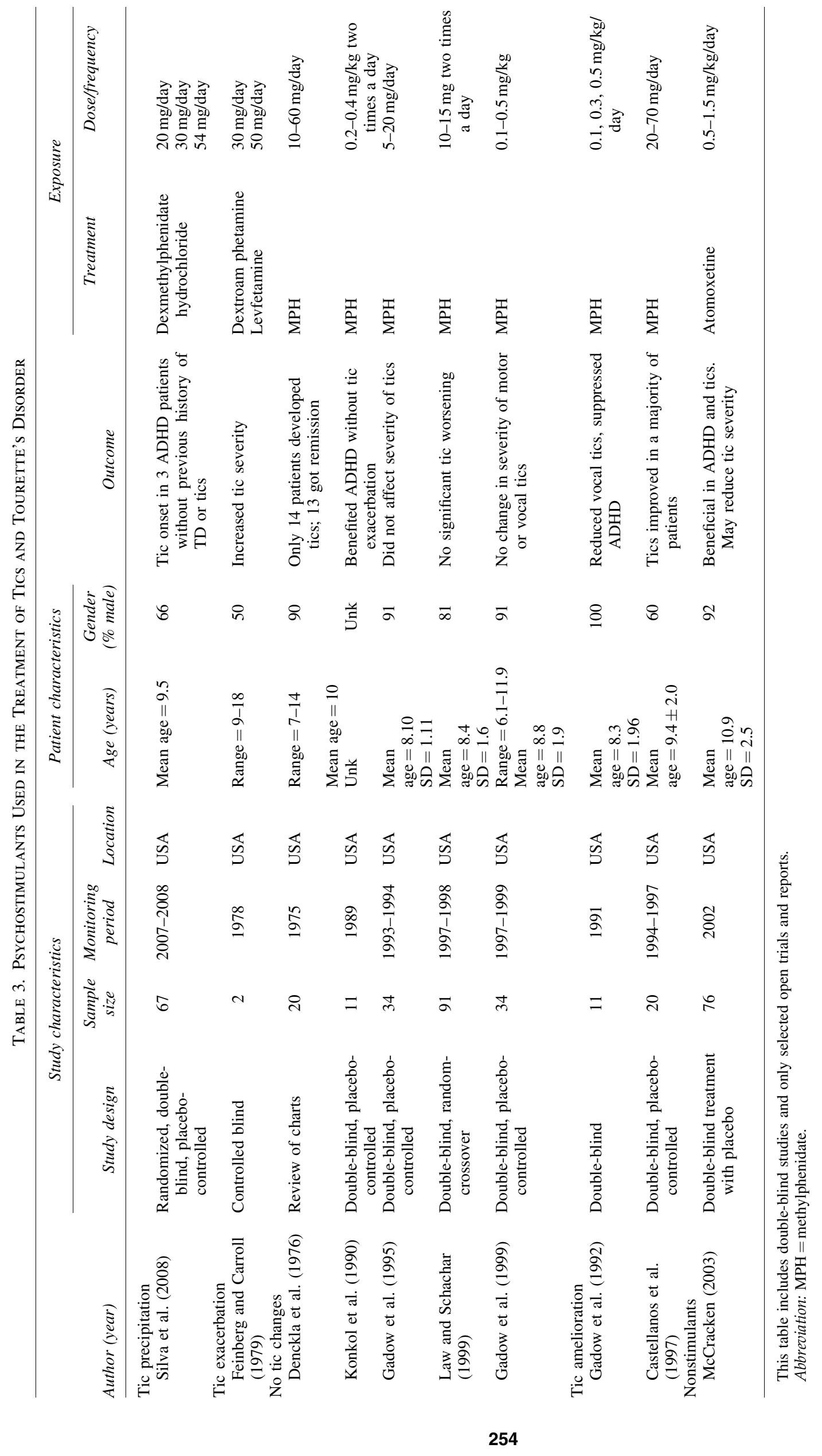


(Leckman et al. 1985). Clonidine can be started at a dose of $0.05 \mathrm{mg} /$ day with gradual titration up to a dose of $0.2-0.3 \mathrm{mg} / \mathrm{day}$.

Guanfacine differs from clonidine in that it appears to be less sedating and less hypotensive. The plasma half-life of guanfacine is about 17 hours (range: 10-30 hours), compared with 12.7 hours (range: 4-10 hours) for clonidine. The efficacy of guanfacine in the treatment of ADHD children with comorbid TD has been evaluated in double-blind, placebo-controlled studies (Chappell et al. 1995; Scahill et al. 2001), with group mean decreases in severity of motor and phonic tics as determined by both clinician and self ratings. Guanfacine can be started at a dose of $0.5 \mathrm{mg} /$ day, with gradual titration up to a dose of $1.5-4 \mathrm{mg} /$ day.

In summary, even when $\alpha$-adrenergic medications may be effective in treating ADHD children with comorbid TD and tics, it should be kept in mind that there are more effective treatment approaches. Some practitioners still use $\alpha$-adrenergic medications as first-line therapy for TD and tics. This appears acceptable on a trial basis before a decision to move to or add a neuroleptic is made.

\section{Selective serotonin reuptake inhibitors}

The role of selective serotonin reuptake inhibitors (SSRIs) in the treatment of tics and TD has not been, to the date, adequately documented. Tic amelioration (and decrease in obsessive thoughts) was reported with sertraline (Table 5) in a TD patient concomitantly receiving pimozide therapy (Buckingham and Gaffney 1993).

Paroxetine was also found to suppress motor tics in a child with TD, congenital albinism, dysthymia, and ADHD concomitantly receiving pimozide (Horrigan and Barhill 1994). However, this patient developed an occulogyric crisis, which subsided when paroxetine was discontinued, pointing to the presence of paroxetine-pimozide interactions.

Fluoxetine was found to be well tolerated by TD patients with OCD in preliminary and open-label trials, significantly reducing tics and OCS (Silvestri et al. 1994). These findings indicate that fluoxetine may be an effective agent for the treatment of OCD in TD patients.

Citalopram and fluvoxamine were used in an open trial in patients with TD (Bajo et al. 1999). The group receiving citalopram was the only one to show significant improvement in motor and vocal tics, approaching statistical significance. No other studies on the use of citalopram for the treatment of TD were found in the literature.

No tic exacerbation was observed in an open-label trial of fluoxetine (20-40 mg/day) in 32 TD patients with OCD (Como and Kurlan 1991). There was a significant reduction in scores on the obsessional inventory, with reports of subjective improvement in obsessions and compulsions without tic exacerbation. Similarly, no tic exacerbation and a dramatic decrease in temper outbursts and distractibility were reported upon the addition of sertraline in a patient with treatment-resistant $\mathrm{ADHD}$ and TD, receiving concomitantly pimozide, clonazepam, and diphenhydramine (Frandenburg and Kando 1994).

Fluvoxamine was used in a study (McDougle et al. 1993) to determine the effects of this medication in a group of OCD patients with comorbid chronic tic disorder compared with another age- and sex-matched group of OCD patients without chronic tic disorder. Clinical improvement occurred in $21 \%$ of OCD patients with chronic tic disorder, compared with a $52 \%$ response rate in OCD patients without tic disorder. Although the clinical improvement in both groups was significant in terms of reduction of OCS, 


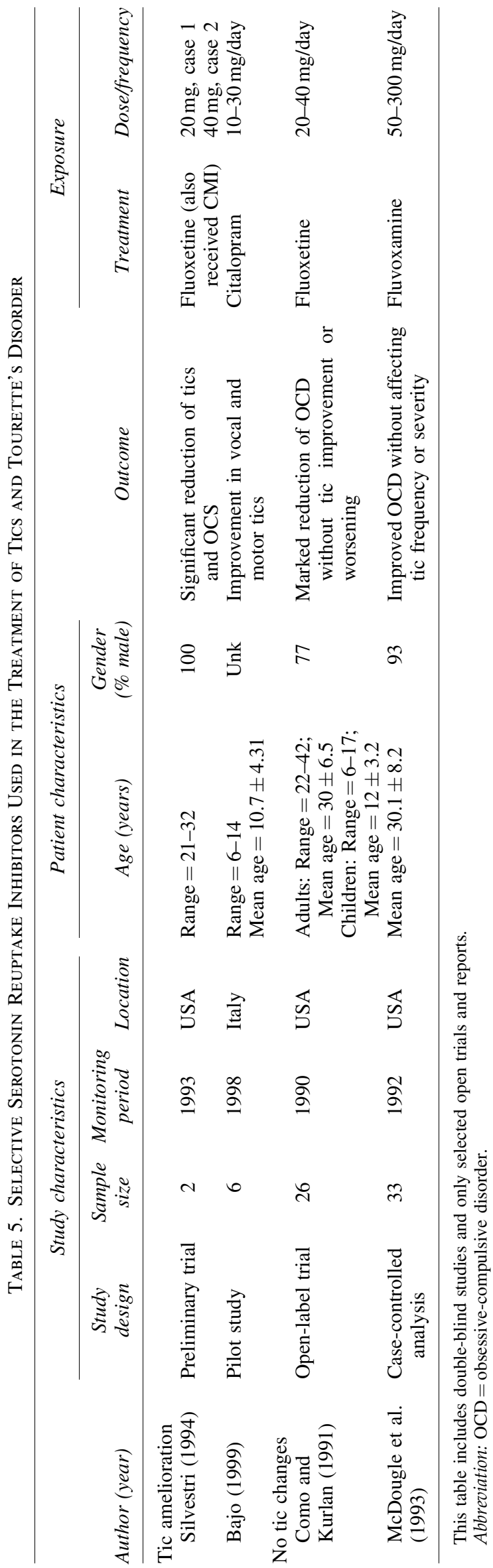

depression, and anxiety symptoms, the results suggested that fluvoxamine may be less effective for patients with tics than without.

Tic emergence (echolalia) was reported fairly recently as an unusual occurrence in a patient with TD taking sertraline (Ghanizadeh 2008).

A literature search failed to identify data regarding the use of trazodone hydrochloride and duloxetine hydrochloride in the treatment of TD or tics.

Among the serotonergic noradrenergic reuptake inhibitors (SNRI), venlafaxine hydrochloride and nefazodone hydrochloride have not been investigated in TD or tics.

In summary, SSRIs have not been individually studied in the treatment of TD or tics. However, the current literature supports a role for SSRIs in the treatment of TD and comorbid disorders, such as OCD, depression, anxiety, and ADHD, with good symptomatic response on comorbid disorders but only mild to moderate beneficial effects on tics.

\section{Atypical and newer antipsychotics}

The atypical antipsychotics block both serotonin and dopamine receptors, potentially having fewer extrapyramidal effects than typical antipsychotics, even when variations in receptor affinity for dopamine, serotonin, and adrenergic receptors have been identified.

Clozapine, although synthesized in the 1960s, was released in this country in the early 1990s (Table 6). In a double-blind, placebo-controlled trial (Caine et al. 1979b), clozapine was used to treat patients with TD, Huntington's disease, and atypical persistent dyskinesia (drug induced). Two subjects with Huntington's disease showed a marked decrease in movements; the other individuals (TD patients included) obtained no therapeutic benefits.

Another researcher (Pfeiffer and Wagner 1994) reviewed the role of clozapine in the treatment of Parkinson's disease and other movement disorders. In this study, some patients with Parkinson's disease showed improvement in tremor and other abnormal movements when given clozapine. A few patients with Huntington's disease responded to clozapine, but no conclusions could be drawn.

Tic amelioration of significant degree has been reported by the use of the following atypical antipsychotics: Risperidone was used in two open-trial studies (Lombroso et al. 1995; Bruun and Budman 1996) in patients with TD and chronic tic disorders who had not responded to conventional treatments. In one of the studies, the patients were assessed with the YGTSS before and after a month of treatment. At the end, 58\% were reported to have improved, and $18 \%$ did not show appreciable change.

In another study, risperidone was used in children and adolescents, three of which had comorbid OCD. The patients were assessed by the YGTSS and the children's version of the Yale-Brown Obsessive Compulsive Scale (YBOCS). Statistically significant improvement in tic scores $(18 \%-66 \%)$ was observed in these patients. Subsequent controlled trials (Dion et al. 2002; Scahill et al. 2003) have demonstrated the superiority of risperidone over placebo for the treatment of TD or tics.

Risperidone is started at a dose of $0.5 \mathrm{mg} /$ day and increased at weekly intervals up to a maximum of $3 \mathrm{mg} /$ day in divided doses. The most common adverse effects are weight gain, sedation, sleep disturbances, and rarely extrapyramidal problems.

Olanzapine appears to be useful in the treatment of patients with TD but has not been adequately investigated. There are a few small studies of TD patients (Stephens et al. 2004; McCracken et al. 2008) receiving olanzapine with improvement of tics. The patients 


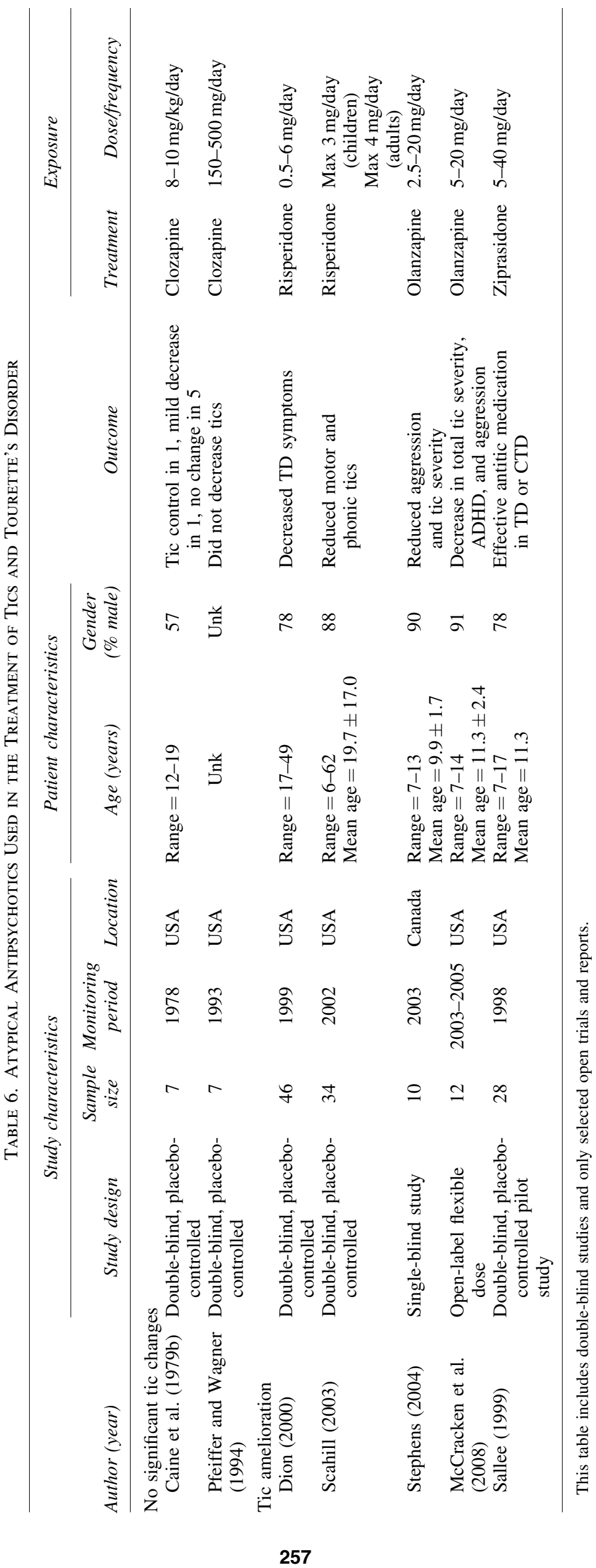


who had not previously used neuroleptics achieved a measurable reduction in symptoms. The patients who previously were refractory or did not tolerate neuroleptic drugs achieved only a partial response. Olanzapine is usually started at a dose of $2.5 \mathrm{mg} / \mathrm{day}$. The side effects include sedation and weight gain.

Ziprazidone was used in a placebo-controlled trial, with encouraging results in children and adolescents with TD (Sallee et al. 2004). This study showed ziprazidone to be similar to risperidone in terms of tic reduction. However, concerns about QTc prolongation and cardiac conduction alterations persist.

Quetiapine has not been formally studied for the treatment of TD. However, there are few case reports indicating a positive response (Párraga et al. 2001).

Aripiprazole has been investigated (Murphy et al. 2005; Bubl et al. 2006) in a few case series of TD patients with favorable results.

In summary, the atypical antipsychotics, with the exception of clozapine, have demonstrated efficacy in the treatment of TD and tics and should be considered an essential component of any treatment plan. They are all explained by the pharmacological feature of combined serotonin-2/dopamine-(5-HT2/D2) antagonism.

\section{Other pharmacologic agents and modalities of treatment}

Anticonvulsants such as carbamazepine, phenytoin, phenobarbital, ethosuximide, primidone, and valproic acid have been used with mixed observations of tic amelioration, exacerbation, and precipitation (Zawadski 1972; Burd et al. 1986).

Newer anticonvulsants such as topiramate and lamotrigine have not been fully investigated. Preliminary studies (Nelson et al. 2007; Jankovic et al. 2010) conducted in children with TD and tics show that topiramate may reduce tic severity by $50 \%$ in add-on therapy patients and by $51 \%$ in monotherapy patients.

Lamotrigine is not indicated for children with tics or TD. Lamotrigine-induced tics, tourettism, and other movement disorders secondary to its use have been reported (Sotero de Menezez et al. 2000; Vance et al. 2004).

Benzodiazepines such as clonazepam, diazepam, chlordiazepoxide, fluorazepam, and clorazepate were used without clear evidence of clinical efficacy (Voulter et al. 1985) and need to be studied. Corticosteroids such as prednisone were used with good response; however, the long-term adverse effects have limited their possible use in TD (Popielarska and Werry 1972).

Beta adrenergic blocking agents (e.g., propranolol) (Sverd et al. 1983), calcium channel blockers (e.g., verapamil) (Walsh et al. 1986), as well as lecithin (Moldofsky and Sandor 1983), naloxone (Berecz et al. 1979), and lithium (Hamra et al. 1983) elicited contradictory findings or were not useful.

Other alternative pharmacologic agents are still under investigation: Baclofen, a gamma-aminobutyric acid (GABA) analog (Singer et al. 2001), selegiline (L-deprenyl), a phenethylamine derivative (Feigin et al. 1996), and tetrabenazine, a monoamine depleting agent (Jankovic and Beach 1997), have shown favorable preliminary results.

Nicotine (Silver et al. 1999) in the form of polacrilex gum or transdermal nicotine patch (TNP) has been used in open-label studies to obtund motor and vocal tics in children and adults. Reduction of tics occurred during chewing of nicotine gum. However, the improvement lasted no longer than 1 hour after chewing. When a TNP was given to subjects who were not responding to dopamine blockers (with some also receiving clonidine), or to SSRIs, motor and vocal tics were decreased $45 \%$ over baseline in $85 \%$ of 35 subjects, within 30 minutes to 3 hours after TNP application.

Botulinum toxin (Salloway et al. 1996), in injection, appears to have a limited role in the treatment of TD. It has been used for localized facial tics and vocal tics (because it appears to decrease the loudness). It was also used (Jankovic 1994) for dystonic motor tics because of its capacity to decrease the actual contraction and the premonitory sensory component.

Although the autoimmune hypothesis for tics and/or OCD is not established, it is viable, and immunomodulatory treatments (Perlmutter et al. 1999) certainly harken back to medieval approaches (plasmapheresis as exchange of "bad blood" for "good blood"). Keeping in mind that these were highly selected treatment-resistant cases, and adding the possibility of placebo effects, it is unlikely to have a solitary explanation for the reported observations.

Transcranial stimulation is a technology in which a brief, powerful magnetic field is generated by a small coil positioned over the skull. Such brain stimulation may affect long-term changes in cortical excitability (George et al. 2001). Deep brain stimulation is a new approach for intractable TD (Vanderwalle et al. 2001). Bilateral stimulation of the postventral internal segment global pallitus (GPi) was performed in a patient with refractory TD (Van der Linden et al. 2002).

Functional imaging studies have evaluated several implicated neurotransmitter systems and focused predominantly on the frequency or severity of tics. The results have been inconclusive and frequently contradictory with little light shed on pathogenetic mechanisms (Adams et al. 2004).

Behavioral interventions, although promising, have not been evaluated in large-scale controlled trials. A recent comprehensive behavioral intervention, compared with supportive therapy and education (Piacentini et al. 2010), resulted in greater improvement in symptom severity among children with TD and chronic tic disorder. Treatment gains were durable, with $87 \%$ of available responders to behavior therapy exhibiting continued benefit for 6 months following treatment.

\section{Conclusions}

An extensive review of double-blind, placebo-controlled clinical trials, open studies, and selected reports on the pharmacological treatment of TD reveals a great deal of confusion. Our initial intention of conducting a meta-analysis did not crystallize because of the difficulties posed by the differences in populations, differences in medication-dose combinations, and differences in outcomes, all capable of influencing the accuracy of the analysis, producing results that would go beyond the objectives of this article. However, baseline pharmacotherapeutic approaches clearly emerge from this review.

The atypical antipsychotics should be the main component of any treatment plan for tics and TD, in combination with SSRIs, as needed, to aid in the treatment of comorbid disorders such as depression, anxiety, OCD, and ADHD. $\alpha$-Adrenergic medications, even when effective for the treatment of ADHD with comorbid tics and TD, should be used only on a trial basis and before a decision is made to move to or add a neuroleptic. TCAs and typical antipsychotics have shown efficacy in the treatment of TD and tics, but their use has been significantly limited by a cohort of side or adverse effects and the current availability of better alternatives.

Medications should be used judiciously, only if strictly needed, and as part of an individualized treatment plan, because each medication has a cohort of potentially adverse and side effects. All 
treatment modalities for TD or tics are still symptomatic, and thus most patients receive more than one medication in addition to psychological treatment.

The variable responses to the multiple approaches mentioned in this historical review should alert us about placebo effects as well as the possible spontaneous fluctuations in tic severity, which are well described in the literature. The fact that many patients are able to suppress their tics voluntarily, for variable periods of time, can also confound evaluation and treatment planning.

The field of TD and tics continues to be an active area of investigation. Thus, the need for studies in larger sample sizes and narrower age ranges of diagnostically homogenous patients as well as an increased awareness of changing perspectives is imperative. For example, metabolic derangements have been demonstrated within regions of the basal ganglia, limbic system, and sensorimotor cortex and are in keeping with the concept of TD as both a motor and behavioral disorder (Adams et al. 2004). Even when TD has long been regarded an involuntary movement disorder, many patients have stated that without the premonitory sensation, there would be no tics. For this reason, it has been suggested that the premonitory urge to tics (Yaryura-Tobias and Neziroglu 1977) places TD within the group of OCD. Thus, the urge may be considered the involuntary component of TD and the performance of the tic merely a voluntary response.

TD symptoms may also markedly improve during adolescence for the vast majority. However, for a minority of patients, the symptoms appear chronic and incurable (Leckman et al. 1998).

Awareness of this natural history forms a crucial framework within which to consider the relatively meager research database and the options that we offer to patients and parents. Because TD does not shorten the life span or lead to physical or intellectual deterioration, improvement in quality of life becomes the main goal of the treatment. The decision to use medications as a component of the treatment should include the patient and the parents and should be made when the symptoms are severe enough to interfere with success at school or work, or compromise normal social development.

\section{Disclosure}

The authors do not have an affiliation with or financial interest in any organization that might pose a conflict of interest.

\section{Acknowledgment}

The authors thank the members of the Vanderbilt University, Department of Biostatistics, for providing assistance with the organization of the tables of this article.

\section{References}

Abuzzahab FS, Anderson FO: Gilles de la Tourette: International Registry. Minn Med 56:492-496, 1973.

Adams JR, Troiano AR, Calne DB: Functional imaging in Tourette's syndrome. J Neural Transm 11:10-11, 2004.

Bajo S, Battaglia M, Pegna C, Bellodi L: Citalopram and fluvoxamine in Tourette's disorder Letter. J Am Acad Child Adolesc Psychiatry 38:230-231, 1999.

Baker EFW: Gilles de la Tourette's disease treated by biomedial frontal leucotomy. Can Med Assoc J 86:746-747, 1962.

Berecz JM, Dysken MW, Davis JM: Naloxone effect in Tourette's syndrome [letter]. Neurology 29:1316-1317, 1979.

Biederman J, Krishnan S, Zhang Y, McGough JJ, Findling RL: Efficacy and tolerability of lisdexamfetamine dimesylate (NRP-104) in children with Attention-deficit/hyperactivity disorder: A phase
III, multicenter, randomized, double-blind, forced-dose, parallelgroup study. Clin Ther 29:450-460, 2007.

Blache R: Chorées graves guérison rapide par les massages et la gymnastique méthodique appliqués. Rapid treatment of severe choreas by massages and application of methodic gymnastics. Gazette hebdomadaire p.787, 1864.

Borison Rl, Ang L, Chang S, Dsyken M, Comaty JE, Davis JM: New pharmacological approaches in the treatment of Tourette's syndrome. In: Advances in Neurology, Vol. 35, Gilles de la Tourette's Syndrome, edited by A.J. Friedhoff, T.N. Chase. New York: Raven Press, 377-382, 1982.

Brain WR: The treatment of tics. Lancet 1:1295-1296, 1928.

Brissaud E: Choree variable. Press Med 13:73-74, 1899.

Bruun RD, Budman CL: Risperidone as a treatment for Tourette's syndrome. J Clin Psychiatry 57:29-31, 1996.

Bruun RD: Clonidine treatment of Tourette's syndrome. In: Advances in Neurology, Vol. 35, Gilles de la Tourette Syndrome, edited by A.J. Friedhoff and T.N. Chase. New York: Raven Press, 403-405, 1982.

Bubl E, Perlov E, Tebartz Van Elst L: Aripiprazole in patients with Tourette's Síndrome. World Biol J Psychiatry 7:123-125, 2006.

Buckingham D, Gaffney G: New Tourette's syndrome treatment. J Am Acad Child Adolesc Psychiatry 32:224, 1993.

Burd L, Kerveshian J, Fisher W, Gascon G: Anticonvulsant medications: An iatrogenic cause of tic disorders. Can J Psychiatry 31:419-423, 1986.

Caine ED, Polinsky RJ, Ebert MH, Rapaport JL, Mikkelsen EJ: Trial of clomipramine and desipramine for Tourette's syndrome. Ann Neurol 5:305, 1979a.

Caine ED, Polinsky RJ, Kartzinel R, Ebert M: The trial use of clozapine for abnormal involuntary movement disorders. Am J Psychiatry 136:317-320, 1979b.

Castellanos FX, Giedd JN, Elia J, Marsh WL, Ritchie GF, Hamburger SD, Rapoport JL: Controlled stimulant treatment of ADHD and comorbid Tourette's: Effects of stimulant and dose. J Am Acad Child Adolesc Psychiatry 36:589-596, 1997.

Challas G, Brauer W: Relief of symptoms with R1625. Am J Psychiatry 120:283-284, 1963.

Chapel JL, Brown N, Jenkins RL: Tourette's disease: Symptomatic relief with haloperidol. Am J Psychiatry 121:608-610, 1964.

Chappell PB, Riddle MA, Scahill L, Lynch KA, Schultz R, Arnsten A: Guanfacine treatment of comorbid attention- deficit hyperactivity disorder and Tourette's syndrome: Preliminary clinical experience. J Am Acad Child Adolesc Psychiatry 34:1140-1146, 1995.

Charcot JM: Lecons du Mardi a la Sarpetriere. Tuesday lessons at the Sarpetriere. Polyclinique 2:13-17, 1888.

Clark DF: Behavior therapy of Gilles de la Tourette's syndrome. $\underline{\text { Brit J }}$ Psychiat 112:771-778, 1966.

Cohen DJ, Detlor J, Young JG, Shaywitz BA: Clonidine ameliorates Gilles de la Tourette syndrome. Arch Gen Psychiatry 37:1350-1357, 1980.

Cohen DJ, Shaywitz BA, Caparulo B, Young JG, Bowers MB Jr.: Chronic multiple tics of Gilles de la Tourette's disease. Arch Gen Psychiatry 35:245-250, 1978.

Comings BG, Comings DE: A controlled study of Tourette's syndrome: Attention deficit disorders and school problems. Am J Hum Genet 41:701-741, 1987.

Como PG, Kurlan R: An open-label trial of fluoxetine for obsessivecompulsive disorder in Gilles de la Tourette's syndrome. Neurology 6:872-874, 1991.

Cruchet R: Étude critique sur le tic convulsif et son traitement gymnastique. Critical study on convulsive tic and its gymnastic. Thése de Bordeaux, 1902.

Debray P, Messerschmitt P, Lonchap D, Herbault M: L'utilization du pimozide en pedopsychiatrie. The use of pimozide in pediatric psychiatry. Nouv Press Med 1:2917-2918, 1972. 
Denckla MB, Bemporad JR, McKay MC: Tics following methylphenidate administration. A report of 20 cases. JAMA 235:13791381, 1976.

Dillon DC, Salzman IJ, Schulsinger DA: The use of imipramine in Tourette's syndrome and attention deficit disorder: Case report. J Clin Psychiatry 46:348-349, 1985.

Dion Y, Annable L, Sabdor P, Chouinard G: Risperidone in the treatment of Tourette's syndrome: a double-blind, placebo controlled trial. J Clin Psychopharmacol 22:31-39, 2002.

Downing RW, Comer NL, Ebert JN: Family dynamics in a case of Gilles de la Tourette's syndrome. J Nerv Ment Dis 138:548-557, 1964.

Erickson MH: Experimental hypnotherapy in Tourette's disease. Am J Clin Hypnother 7:325-331, 1964.

Faux EJ: Gilles de la Tourette's syndrome: Social psychiatric management. Arch Gen Psychiatry 14:139-142, 1966.

Feigin A, Kurlan R, McDermott MP, Beach H, Dimitsopulos T, Brower CA, Chapieski L, Trinidad K, Como P, Jankovic J: A control trial of deprenyl in children with Tourette's syndrome and attention-deficit hyperactivity disorder. Neurology 46:965-968, 1996.

Feinberg M, Carroll BJ: Effects of dopamine agonists and antagonists in Tourette's disease. Arch Gen Psychiatry 36:979-985, 1979.

Frandenburg FR, Kando JC: Sertraline treatment of attention deficit hyperactivity disorder and Tourette's syndrome. J Clin Psychopharmacol 14:359-360, 1994.

Fras I: Gilles de la Tourette's syndrome: Effects of tricyclic antidepressants. NY J Med 78:1230-1232, 1978.

Fras I, Karlavage J: The use of methylphenidate and imipramine in Gilles de la Tourette's disease in children. Am J Psychiatry 134:195-197, 1977.

Gadow KD, Nolan EE, Sverd J: Methylphenidate in hyperactive boys with comorbid tic disorder. II. Short- term behavioral effects in school settings. J Am Acad Child Adolesc Psychiatry 31:462-471, 1992.

Gadow KD, Sverd J, Sprafkin J, Nolan EE, Grossman S: Long-term methylphenidate therapy in children with comorbid ADHD and chronic multiple tic disorder. Arch Gen Psychiatry 56:330-336, 1999.

Gadow KD, Sverd J, Sprafkin J: Efficacy of methylphenidate for attention deficit hyperactivity disorder in children with tic disorder. Arch Gen Psychiatry 52:444-455, 1995.

Gadow KD, Sverd J: Stimulants for ADHD in child patients with Tourette's syndrome: The issue of relative risk. J Dev Behav Pediatr 11:269-271, 1990.

George MS, Sallee FR, Nahas Z, Oliver NC, Wasserman EM: Transcranial magnetic stimulation (TMS) as a research tool in Tourette syndrome and related disorders. Adv Neurol 85:225-235, 2001.

Ghanizadeh A: The emergence of echolalia while taking sertraline in a patient with Tourette's syndrome. Dev Med Child Neurol 50:398399, 2008.

Gilles de la Tourette G: Étude sur une affection nerveuse charactérisée par de l'incoordination motrice accompagnée d'echolalie et de coprolalie. Study of a nervous affection characterized by motor uncoordination accompanied by echolaly and coprolaly. Arch Neurol 25:10-41, 1885.

Goetz CG, Tanner CM, Klawans HL: Fluphenazine and multifocal tic disorders. Arch Neurol 41:271-272, 1984.

Goetz CG, Tanner CM, Wilson RS, Shannon KM: A rating scale for Gilles de la Tourette's syndrome: Description, reliability and treatment. Neurology 37:1542-1544, 1987.

Golden GS: Gilles de la Tourette's syndrome following methylphenidate administration. Dev Med Child Neurol 16:76-78, 1974.

Golden GS: The effect of the central nervous systems stimulants on Tourette syndrome. Ann Neurol 2:69-70, 1977.
Guinon G: Tic convulsifs et hysterie. Convulsive tics and hysteria Rev Med 7:509-519, 1887.

Hamra BJ, Dunner FH, Larson C: Remission of tics with lithium therapy: Case report. J Clin Psychiatry 44:73-74, 1983.

Horrigan PJ, Barhill LJ: Paroxetine-pimozide drug interaction (Letter). J Am Acad Child Psychiatry 33:1060-1061, 1994.

Itard JMG: Mémoire sur quelques fonctions involuntaires des appareils de la locomotion, de la prehension et de la voix, 1825 .

Jankovic J, Beach J: Long-term effects of tetrabenazine in hyperkinec movement disorders. Neurology 48:358-362, 1997.

Jankovic J, Jimenez-Shahed J, Brown LW: A randomised, doubleblind, placebo-controlled study of topiramate in the treatment of Tourette syndrome. J Neurol Neurosurg Psychiatry 81:70-73, 2010.

Jankovic J: Botulinum toxin in the treatment of dystonic tics. Mov Disord 9:347-349, 1994.

Konkol RJ, Fisher M, Newby RF: Double -blind, placebo controlled stimulants trial in children with Tourette's syndrome and attentiondeficit disorder. Ann Neurol 28:424, 1990.

Law SF, Schachar RJ: Do typical clinical doses of methylphenidate cause tics in children treated for attention-deficit hyperactivity disorder? J Am Acad Child Adolesc Psychiatry 38: 944-951, 1999.

Leckman JF, Detlor J, Harcherik DF, Ort S, Shaywitz BA, Cohen DJ: Short and long-term treatment of Tourette's syndrome with clonidine: A clinical perspective. Neurology 35:343-351, 1985.

Leckman JF, Zhang H, Vitale A, Lahnin F, Lynch K, Bondi C, Kim YS, Peterson BS: Course of tic severity in Tourette's syndrome: The first two decades. Pediatrics 12:14-19, 1998.

Lee TS, Lee D, Lombroso PJ, King R: Atomoxetine and tics in ADHD. J Am Acad Child Adolesc Psychiatry 43(9): 1068-1069, 2005.

Lombroso PJ, Scahill L, King RA, Lynch KA, Chappell PB, Peterson BS, McDougle CJ, Leckman JF: Risperidone treatment of children and adolescents with chronic tic disorders: A preliminary report. J Am Acad Child Adolesc Psychiatry 34:1147-1152, 1995.

Lowe TL, Cohen DJ, Detlor J, Kremenitzer MW, Shaywitz BA: Stimulant medications precipitate Tourette's syndrome. JAMA 247:1729-1731, 1982.

Mahler MS, Gross IH: Psychotherapeutic study of a typical case with tics syndrome. Nerv Child 4:359-373, 1945.

Mahler MS, Luke JA: Outcome of the tic syndrome. J Nerv Ment Dis 103:433-445, 1946.

Mahler MS, Rangell L: A psychosomatic study of maladie des tics (Gilles de la Tourette's disease). Psychiatr Q 17:579-603, 1943.

McCracken J, Sallee FR, Leonard H: Improvement of ADHD by atomoxetine in children with tic disorders. Presented at American Academy of Child and Adolescent Psychiatry, October 14-19, Miami, FL, 2003.

McCracken JT, Suddath R, Chang S, Thakur S, Piacentini J: Effectiveness and tolerability of open label olanzapine in children and adolescents with Tourette's syndrome. J Child Adolesc Psychopharmacol 18:501-508, 2008.

McDonald IJ: A case of Gilles de la Tourette's Syndrome with some etiological observations. Brit J Psychiatry 109:206-210, 1963.

McDougle CJ, Goodman WK, Leckman JF, Barr LC, Heninger GR, Price LH: The efficacy of fluvoxamine in obsessive-compulsive disorder: Effects of comorbid chronic tic disorder. J Clin Psychopharmacol 13:354-358, 1993.

Meige H, Feindel E: Les Tics et leur traitement. Paris: Masson, 1902.

Meige H, Feindel E: Tics and Their Treatment, Translated and edited by SAK Wilson. New York: William Wood and Co., 1907.

Messiha FS, Knopp W: A study of endogenous dopamine metabolism in Gilles de la Tourette disease. Dis Nerv Syst 37:470-475, 1976.

Mikkelsen EJ, Detlor J, Cohen DJ: School avoidance and social phobia triggered by haloperidol in patients with Tourette's disorder. Am J Psychiatry 138:1572-1576, 1981. 
Mitchell E, Mattews KL: Gilles de la Tourette's disorder associated with pemoline. Am J Psychiatry 137:1618-1619, 1980.

Moldofsky H, Sandor P: Lecithin in the treatment of Gilles de la Tourette's syndrome. Am J Psychiatry 140:1627-1629, 1983.

Murphy TK, Bengston MA, Soto O, Edge PJ, Sajid MW, Shapira N, Yang M: Case series on the use of aripiprazole for Tourette's Syndrome. Int J Neuropsychopharmacol 25:94-96, 2005.

Nelson TY, Bost MT, Lesser PS: Topiramate in children and adolescents with Tourette syndrome: A case series. J Pediatric Neurol 5:15-19, 2007.

Palumbo D, Spencer T, Lynch J: Co-Chien H, Faraone SV: Emergence of tics in children with ADHD: Impact of once-daily OROS methylphenidate therapy. J Child Adolesc Psychopharmacol 14:185-194, 2004.

Parihk MD, Abhyanka RR, Bajaj N, Doongaji DR: Penfluridol in the treatment of Gilles de la Tourette's syndrome. Neurology 27:174177, 1979.

Párraga HC, Cochran M: Emergence of motor and vocal tics during imipramine administration in two children. J Child Adolesc Psychopharmacol 3:227-234, 1992.

Párraga HC, Parraga M, Woodward R, Fenning P: Quetiapine Treatment of children with Tourette's syndrome: Report of two cases. J Child Adolesc Psychopharmacol 11:187-191, 2001.

Perlmutter SJ, Leitman SF, Garvey MA, Hamburger S, Feldman E, Leonard HL, Swedo SE: Therapeutic plasma exchange and intravenous immunoglobulin for obsessive-compulsive disorder and tic disorders in childhood. Lancet 354:1153-1158, 1999.

Pfeiffer C, Wagner ML: Clozapine therapy for Parkinson's disease and other movement disorders. Am J Hosp Pharm 51:3047-3053, 1994.

Piacentini J, Woods D, Scahill L, Wilhelm S, Peterson A, Chang S, Ginsburg G, Deckersbach T, Dziura J, Levi-Pearl S, Walkup J: Behavior therapy for children with Tourette disorder: A randomized controlled trial. JAMA 303:1929-1937, 2010.

Pollak MA, Cohen NL, Friedhoff AJ: Gilles de la Tourette's syndrome: Familial occurrence and precipitation by methylphenidate therapy. Arch Neurol 34:630-632, 1977.

Popielarska HC, Werry JS: Psychopathological Disorders of Childhood. New York: Wiley, 1972.

Price RA, Leckman JF, Pauls DL,Cohen DJ, Kidd KK: Gilles de la Tourette's syndrome: Tics and central nervous system stimulants in twins and non twins. Neurology 36:232-237, 1986

Ratzoni G, Hermesch H, Brandt N, Lauffer M, Munitz H: Clomipramine efficacy in tics, obsessions and compulsions in Tourette's syndrome and obsessive compulsive disorder: A case study. Biol Psychiatry 27:95-98, 1990.

Regeur L, Pakkenberg B, Fog R, Akkenberg H: Clinical features and long term treatment with Pimozide in 65 patients with Gilles de la Tourette's syndrome. J Neurol Neurosurg Psychiatry 99:791-795, 1986.

Riddle MA, Hardin MT, Cho SC, Woolston JL, Leckman JF: Desipramine treatment of boys with attention-deficit hyperactivity disorder and tics. Preliminary clinical experience. J Am Acad Child Adolesc Psychiatry 27:811-814, 1988.

Sallee FR, Kurlan R, Goetz CG, Sinmger H, Singer H, Scahill L, Law G, Dittman VM, Chapell PB: Ziprasidone treatment of children and adolescents with Tourette's syndrome: A pilot study. J Am Acad Child Adolesc Psychiatry 39:292-299, 2004.

Sallee FR, Nesbitt 1, Jackson C, Sine L, Sethuraman G: Relative efficacy of haloperidol and pimozide in children and adolescents with Tourette's disorder. Am J Psychiatry 154:1057-1062, 1997.

Salloway S, Stewart CF, Israeli I: Botulinum toxin for refractory vocal tics. Mov Disord 11:746-748, 1996.

Sandyk R, Bamford CR: Beneficial effects of imipramine on Tourette's syndrome. Int J Neurosci 39:27-29, 1988.
Scahill L, Chappell PB, Kim YS, Schultz RT, Katsovich L, Shepherd E, Arnsten A Cohen DJ, Leckman JF: A placebo-controlled study of guanfacine in the treatment of children with tic disorders and attention deficit hyperactivity disorder. Am J Psychiatry 158:10671074, 2001.

Scahill L, Leckman JF, Schultz RT, Katsovich L, Peterson BS: A placebo controlled trial of risperdone in Tourette's Syndrome. Neurology 60:1130-1135, 2003.

Seignot MJN: Un cas de maladie des tics de Gilles de la Tourette gueri par le R-1625. A case of Gilles de la Tourette's disease treated with R-1625. Ann Med Psychol 119:578-579, 1961.

Shapiro AK, Shapiro E: Controlled study of pimozide vs. placebo in Tourette's syndrome. J Am Acad Child Psychiatry 23:161-173, 1984.

Shapiro AK, Shapiro E: Do stimulants provoke, cause or exacerbate tics and Tourette syndrome? Comp Psychiatry 22:265-273, 1981.

Shapiro AK, Shapiro E, Eisenkraft GJ: Treatment of Tourette's disorder with penfluridol. Compr Psychiatry 24:327-331, 1983a.

Shapiro AK, Shapiro E, Eisenkraft GJ: Treatment of Gilles de la Tourette's syndrome with clonidine and neuroleptics. Arch Gen Psychiatry 40:1235-1240, 1983b.

Shapiro AK, Shapiro E, Wayne HL: Treatment of Gilles de la Tourette's syndrome with haloperidol: Review of 34 cases. Arch Gen Psychiatry 28:92-96, 1973.

Shapiro AK, Shapiro E, Young JG, Feinberg TE: Gilles de la Tourette's Syndrome, 2nd edition. New York: Raven Press, 387-390, 1988.

Shapiro AK, Shapiro ES, Bruun RD, Sweet RD: Gilles de la Tourette's Syndrome. New York: Raven Press, 119-141, 1978.

Silva R, Muniz R, Pestreich L, Brams M, Mao A, Childress A, Wang $\mathrm{J}$ : Dexmethylphenidate extended-release capsules in children with attention-deficit hyperactivity disorder. J Am Acad Child Adolesc Psychiatry 47: 199-208, 2008.

Silver AA, Shytle RD, Sanberg PA: Clinical Experience with transdermal nicotine patch in Tourette syndrome. CNS Spectrums 4:6876, 1999.

Silvestri R, Raffaele M, De Domenico P, Tisano A, Lagana A, Di Perri R: Serotoninergic agents in the treatment of Gilles de la Tourette's syndrome. Acta Neurol 49:58-63, 1994.

Singer HS, Brown J, Quaskey S, Rosenberg LA, Mellits ED, Denckla MB: The treatment of attention-deficit hyperactivity disorder in Tourette's syndrome: A double-blind placebo controlled study with clonidine and desipramine. Pediatrics 95:74-81, 1995.

Singer HS, Wendlandt J, Krieger M, Giuliano J: Baclofen treatment in Tourette's syndrome: A double-blind, placebo-controlled, crossover trial. Neurology 56:599-604, 2001.

Singer K: Gilles de la Tourette's Disease. Am J Psychiatry 120:80-81, 1963.

Sotero de Menezez MA, Rho JM, Murphy P, Cheyette S: Lamotrigine-induced tic disorder: report of five pediatric cases. Epilepsy 41:862-867, 2000.

Spencer T, Biederman J, Kerman K, Steingard R, Wilens T: Desipramine treatment of children with attention deficit hyperactivity disorder and tic disorder or Tourette's syndrome. J Am Acad Child Adolesc Psychiatry 32:354-360, 1993a.

Spencer T, Biederman J, Wilens T, Steingard R, Geist D: Nortriptyline treatment of children with attention deficit hyperactivity disorder and tic disorder or Tourette's syndrome. J Am Acad Child Adolesc Psychiatry 32:205-210, 1993b.

Stephens RJ, Bassel C, Sandor P: Olanzepine in the treatment of aggression and tics in children with Tourette's syndromeA pilot study. J Child Adolesc Psychopharmacol 14:255-266, 2004. 
Sverd J, Cohen S, Camp JA: Effects of propranolol in Tourette syndrome. J Autism Dev Disor 13:207-213, 1983.

Sverd J: Imipramine treatment of panic disorder in a boy with Tourette's syndrome. J Clin Psychiatry 49:31-32, 1988.

Trousseau A: Clinique medicale de l'hotel Dieu de Paris quatrieme edition. Medical clinic at Dieu's hotel in Paris, Fourth edition. Paris: Balliere, 3, 1873.

Van der Linden C, Colle H, Vanderwalle V, Alessi G, Rijckaert D, De Waele L: Successful treatment of tics with bilateral internal pallidum (GPi) stimulation in a 27 year old male patient with Gilles de la Tourette's syndrome. Mov Disord 17:1130, 2002.

Vance CK, Kanner AM, Smith MC: Sydenham's-like picture and touretism as related to lamotrigine toxicity. Epilepsy 45 (Suppl 7):137, 2004.

Vanderwalle V, van der Linden C, Groenewegen HJ, Caemaert J: Stereotactic treatment of Gilles de la Tourette's syndrome by high frequency stimulation of thalamus. Lancet 353:724, 2001.

Voulter L, Bressamn SB, Fahn S: Treatment of tic disorder with clonazepam. J Can Sci Neurol 12:172-173, 1985.
Walsh TL, Lavenstein B, Licamele WL, Bronheim S, O'Leary JO: Calcium antagonists in the treatment of Tourette's disorder. Am J Psychiatry 143:1467-1468, 1986.

Yaryura-Tobias JA: Clomipramine in Gilles de la Tourette disease. Am J Psychiatry 132-1221, 1975.

Yaryura-Tobias JA, Neziroglu FA: Gilles de la Tourette syndrome: A new clinico-therapeutic approach. Prog Neuropsychopharmacol 1:355-358, 1977.

Zawadski A: Treatment of Maladie des tics with carbamazepine. Pediatri Pol 47:1105-1110, 1972.

Address correspondence to:

Humberto C. Párraga, M.D. Department of Child Psychiatry

Fourth Street Clinic 922 South Fourth Street Springfield, IL 627003

E-mail: parragahc@aol.com 